\title{
Recurrent Achalasia after Surgical Treatment
}

\author{
AHMED MONIER, M.D.; ALI SALEM, M.D.; MOSTAFA ABU ZIED, M.D.; AMR SANAD, M.B.B.Ch. and \\ MOHAMED DOSOKY, M.D.
}

The Department of Gastrointestinal Surgery Center, Faculty of Medicine, Mansoura Univeristy

\begin{abstract}
Background: Laparoscopic Heller myotomy with a partial fundoplication is the mainstay of surgical treatment of achalasia of the cardia. The failure of surgical therapy in the treatment of achalasia is related to different causes that have not yet been conclusively defined in the literature.

Aim of Study: To analyze different predictors of recurrence of achalasia after surgical treatment.

Patients and Methods: This is a retrospective study that was conducted to patients who underwent surgical interventions for achalasia at Gastrointestinal Surgical center (GISC), Mansoura University, Egypt during the period between January 2007 and December 2017. The aim of this study is to analyze different predictors of recurrence of achalasia after surgical treatment.

Results: 191 patients underwent Heller cardiomyotomy with a mean age of $37.08 \pm 14.98$ years and mean body mass index of $24.78 \pm 6.98 \mathrm{~kg} / \mathrm{m}^{2}$. Recurrence of achalasia occurred in $33(17.3 \%)$ patients. Surgical remyotomy was performed in $14(42.42 \%)$ patients while balloon dilatation was performed in $19(57.6 \%)$ patients. Factors associated with higher recurrence rate were higher Eckhardt Score and younger age $(p<0.05)$.

Conclusion: Age was negatively correlated with recurrence. However, Eckhardt score was positively correlated with it. Moreover, binary logistic regression revealed that younger age is a strong predictor of recurrence after surgical management of achalasia.
\end{abstract}

Key Words: Achalasia-Heller's cardiomyotomy - Surgical treatment failure.

\section{Introduction}

ESOPHAGEAL achalasia is motility disorder characterized by the absence of esophageal peristalsis and failure of the lower esophageal sphincter to relax in response to swallowing. Treatment of achalasia aims to release of esophageal outlet obstruction, while minimizing gastroesophageal reflux. Laparoscopic Heller myotomy with a partial

Correspondence to: Dr. Ahmed Monier, The Department of Gastrointestinal Surgery Center, Faculty of Medicine, Mansoura Univeristy fundoplication is a reasonable option to treat achalasia and can be performed with minimal morbidity and almost zero mortality when patients are appropriately selected [1].

The failure of surgical therapy in the treatment of achalasia is related to different causes that have not yet been conclusively defined in the literature. The causes include gastroesophageal reflux, late development of carcinoma, excessively tight fundoplication, pre-existence of a decompensated sigmoid-shaped megaesophagus, and inadequate myotomy [2] .

Even though the operation has a very high success rate, some patients eventually experience recurrence of symptoms and need further treatment, particularly if the first operation was done at an early age. When this happens, it is important to perform a careful work-up to try to identify the cause and to have a tailored treatment plan [3]

The aim of this study is to analyze different predictors of recurrence of achalasia after surgical treatment.

\section{Patients and Methods}

This is a retrospective study that was conducted to patients who underwent surgical interventions for achalasia at Gastrointestinal Surgical center (GISC), Mansoura University, Egypt during the period between January 2007 and December 2017. Data for this study were retrieved from the internal web-based registry system supplemented by medical records of the patients included in the medical archive. A written consent was obtained from all cases before the operation after the explanation of advantages, and drawbacks of surgical intervention. The study was approved by the local ethical committee.

Data collected included, complete history regarding age, sex, pre-existing medical co morbid- 
ities, and special habits. Besides, achalasia symptoms were discussed in details with every patient including dysphagia, regurgitation, chest pain, heart burn, and weight loss. Physical examination was performed for all study cases. Routine preoperative laboratory investigations including CBC, renal functions tests, liver function tests, bleeding profile, and viral markers were ordered for all study cases. Barium swallow and upper gastrointestinal endoscopy were done in all cases. Esophageal manometry was ordered for every case.

Surgical technique entailed long esophageal myotomy was extended to $7 \mathrm{~cm}$ above cardia and down to $2-3 \mathrm{~cm}$ below it. Dor fundoplication was done after that to protect against reflux. All cases were called for follow up and to assess the recurrence symptoms in these cases. Patients were asked about the degree of relief of symptoms after operation. Patients with persistent or recurrence symptoms were assessed by endoscopy, barium study, and manometry. Recurrent cases were managed either by endoscopic balloon dilatation, or surgical re-myotomy.

Categorical data will be presented as number and percentage. Continuous data will be presented as mean and standard deviation or as median and range. Evaluation of predictors of recurrent achalasia will be done by bivariate correlation for univariate analysis and binary logistic regression for multivariate analysis. Data management will be done by program SPSS v-20 for windows. A $p$ value $<0.05$ will be considered significant.

\section{Results}

During the study period, 191 patients with achalasia were surgically managed. Patient demographics and manometric features are listed in Tables $(1,2)$. Surgical details of the studied population are summarized in Table (3). Follow-up results are shown in table 4. Univariate analysis of predictive factors of recurrence is summarized in Table (5). A binary logistic regression was run to determine possible predictors in the studied variables of the recurrence among the patients in the study population. There was homoscedasticity and normality of the residuals. The binary logistic regression model was statistically significant $(\chi=9.22$, df $1, p=0.002)$. Among all variables, only age was significant as a predictor of recurrence $(\mathrm{F}=8.49$, df $1, p=0.004)$, As illustrated in Table (6).

Table (1): Demographics, medical and surgical history of the studied patients.

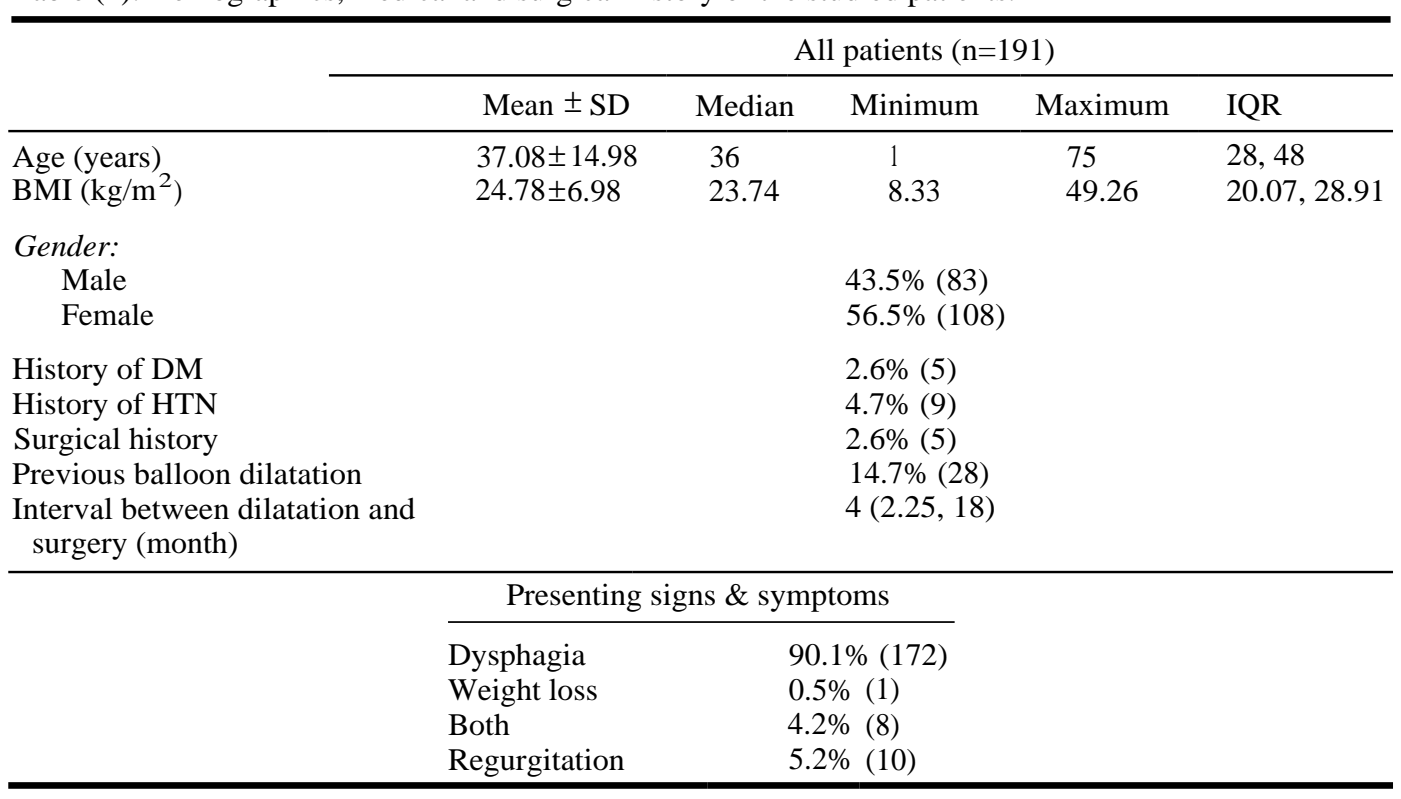

Table (2): Results of the preoperative esophageal manometry in the studied subjects.

\begin{tabular}{lllccc}
\hline & \multicolumn{5}{c}{ Esophageal manometry patients (n=191) } \\
\cline { 2 - 6 } & Mean \pm SD & Median & Minimum & Maximum & IQR \\
\hline LES Pressure & $46.37 \pm 19.63$ & 45.00 & 4.00 & 107.40 & $29.70,56.63$ \\
Relaxation & $59.13 \pm 20.97$ & 56.20 & 2.00 & 100.00 & $43.85,73.00$ \\
Spontaneous Movement & $92.77 \pm 22.06$ & 100.00 & 0.00 & 100.00 & $100.00,100.00$ \\
Normal movement & $2.26 \pm 11.12$ & 0.00 & 0.00 & 100.00 & $0.00,0.00$ \\
LES length & $3.62 \pm 1.20$ & 3.75 & 1.00 & 8.00 & $2.50,4.20$ \\
\hline
\end{tabular}

Data is expressed as mean and standard deviation, Median, Minimum, Maximum and Inter-quartile range. 
Table (3): Operative detials.

\begin{tabular}{|c|c|c|c|c|c|c|}
\hline & \multicolumn{4}{|c|}{ All patients $(n=191)$} & & \\
\hline & \multicolumn{4}{|l|}{ Type: } & & \\
\hline & \multicolumn{3}{|c|}{ Open } & $31.9 \%(61)$ & & \\
\hline & \multicolumn{3}{|c|}{ Laparoscopy } & $63.9 \%(122)$ & & \\
\hline & \multicolumn{3}{|c|}{ Failed Laparoscopy } & $4.2 \%(8)$ & & \\
\hline & \multicolumn{3}{|c|}{ Dor fundoplication } & $96.9 \%(185)$ & & \\
\hline & \multicolumn{3}{|c|}{ Crural fixation } & $8.4 \%(16)$ & & \\
\hline & & Mean \pm SD & Median & Minimum & Maximum & IQR \\
\hline Length of esophageal myot & tomy & $5.87 \pm 1.38$ & 6.00 & 2.00 & 10.00 & $5.00,7.00$ \\
\hline Length of myotomy below & Cardia & $1.71 \pm 0.66$ & 2.00 & 0.00 & 4.00 & $1.00,2.00$ \\
\hline Operative time & & $1.80 \pm 0.58$ & 2.00 & 1.00 & 4.00 & $1.50,2.00$ \\
\hline \multirow[t]{14}{*}{ Hospital Stay } & & $3.07 \pm 1.94$ & 2.00 & 1.00 & 15.00 & $2.00,4.00$ \\
\hline & \multicolumn{6}{|c|}{ Intraoperative complications: } \\
\hline & \multicolumn{3}{|c|}{ Mucosal Perforation } & $15.2 \%(29)$ & & \\
\hline & \multicolumn{3}{|c|}{ Port site Bleeding } & $0.5 \%(1)$ & & \\
\hline & \multicolumn{3}{|c|}{ Injury to surround structures } & $1 \%(2)$ & & \\
\hline & \multicolumn{6}{|c|}{$\begin{array}{l}\text { Management of intra-operative } \\
\text { complications }(n=32) \text { : }\end{array}$} \\
\hline & \multicolumn{3}{|c|}{ Laparoscopic repair } & $68.8 \%(22)$ & & \\
\hline & \multicolumn{3}{|c|}{ Convert to open } & $6.3 \%(2)$ & & \\
\hline & \multicolumn{3}{|c|}{ Open Repair } & $25 \%(8)$ & & \\
\hline & \multicolumn{3}{|c|}{ Chest infection } & $0 \%(0)$ & & \\
\hline & \multicolumn{3}{|c|}{ Pleural effusion } & $1 \%(1)$ & & \\
\hline & \multicolumn{3}{|l|}{ Leak } & $0 \%(0)$ & & \\
\hline & \multicolumn{3}{|c|}{ Pneumothorax } & $2.6 \%(5)$ & & \\
\hline & \multicolumn{3}{|c|}{ Abdominal collection } & $0.5 \%(1)$ & & \\
\hline
\end{tabular}

Tables (4): Follow-up results of the studied patients.

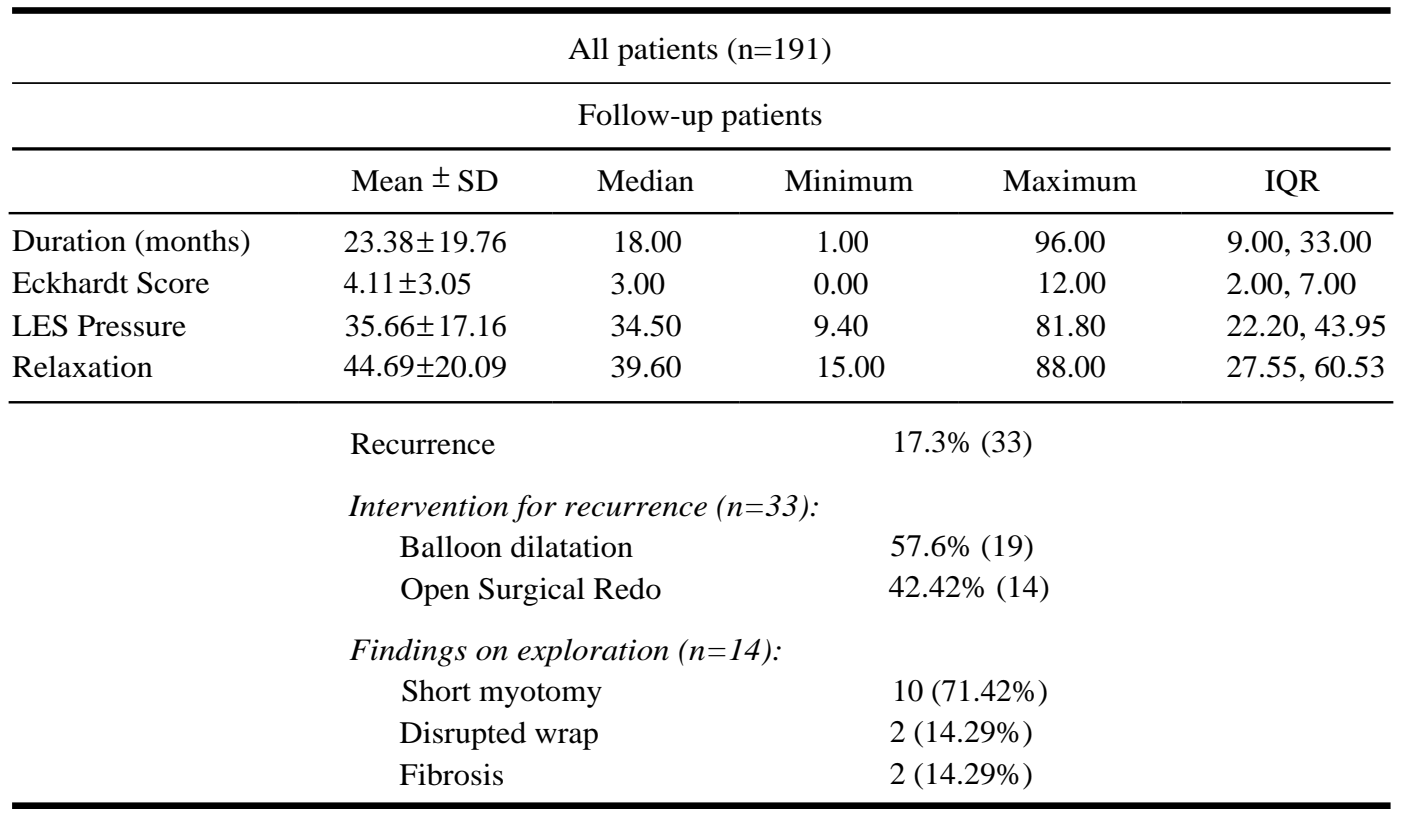

Data is expressed as percentage and number. 
Table (5): Correlation between recurrence and quantitative data.

\begin{tabular}{lll}
\hline & Correlation & $p$ \\
& Coefficient & $p$ \\
\hline Age & -0.216 & 0.003 \\
BMI & -0.064 & 0.383 \\
Duration of symptoms & 0.104 & 0.151 \\
Interval between dilatation and surgery & 0.109 & 0.581 \\
Number of dilatation sets & 0.223 & 0.255 \\
LES Pressure & -0.014 & 0.873 \\
Relaxation & -0.049 & 0.568 \\
Normal movement & -0.102 & 0.239 \\
Length of esophageal myotomy & 0.018 & 0.838 \\
LES length & 0.097 & 0.183 \\
Length of myotomy below Cardia & -0.065 & 0.369 \\
Eckhardt Score & 0.875 & $<0.001$ \\
Female gender & 0.01 & 0.896 \\
Positive surgical history & -0.099 & 0.175 \\
Dysphagia & -0.079 & 0.275 \\
Dysphagia \& weight loss & 0.112 & 0.123 \\
regrgitation & -0.045 & 0.534 \\
Balloon dilatation & 0.046 & 0.532 \\
Dilated esophagus by barium & -0.042 & 0.568 \\
Manometry & 0.107 & 0.140 \\
Spastic cardia & 0.119 & 0.1 \\
Pinpoint cardia & -0.039 & 0.607 \\
Normal cardia & -0.078 & 0.303 \\
Dilated esophagus by Endoscopy & 0.031 & 0.681 \\
Open surgery & -0.105 & 0.148 \\
Laparoscopic surgery & 0.113 & 0.119 \\
Failed laparoscopic surgery & -0.026 & 0.717 \\
Dor fundoplication & 0.003 & 0.968 \\
Crural fixation & 0.025 & 0.729 \\
Presence of intra-operative complications & -0.020 & 0.788 \\
\hline & & \\
\hline & & \\
& &
\end{tabular}

Table (6): Age as a predictor of recurrent achalasia after surgery.

\begin{tabular}{lcccc}
\hline Variable & $\mathrm{B}$ & $\mathrm{F}$ & $p$ & Constant \\
\hline Age & -0.041 & 8.49 & 0.004 & -0.176 \\
\hline
\end{tabular}

Table (7): Eckardt score (clinical scoring system for achalasia).

\begin{tabular}{lllll}
\hline Score & $\begin{array}{c}\text { Weight } \\
\text { loss }(\mathrm{kg})\end{array}$ & Dysphagia & Regurgitation & $\begin{array}{c}\text { Retrosternal } \\
\text { pain }\end{array}$ \\
\hline 0 & None & None & None & None \\
1 & $<5$ & Occasional & Occasional & Occasional \\
2 & $5-10$ & Daily & Daily & $\begin{array}{l}\text { Daily } \\
3\end{array}$ \\
\hline
\end{tabular}

It ranges from 0 to 12 .

\section{Discussion}

The pathophysiology of achalasia is still mysterious, and the methods of management which are presently accessible are planned only to palliate its characteristic symptoms through disturbing, weakening or cutting the LES muscle. Surgery is possibly the most valuable procedure to reach this goal and that myotomy by using laparoscopy is as efficient as open surgery, on the other hand this management could moreover be unsuccessful in some cases [4]. Risk factors for lesser rates of success subsequent to surgical treatment are severe preoperative dysphagia, low LES pressures and severe esophageal dilation [5]

About $89 \%$ (77\% to $100 \%$ ) of patients report symptom improvement after laparoscopic Heller myotomy [6] . Long-term follow-up shows that symptom and quality of life improvement are maintained [7]. A long-term follow-up by Csendes et al., shows that failure rates after surgical treatment for achalasia are $7 \%$ after 10 years and 35\% after 30 years of follow-up. The authors of this study conclude that this may be due to a progressive increase in esophageal exposure to abnormal gastric reflux, which they demonstrated using $\mathrm{pH}$-metry [8] while in our study, recurrence was encountered in 33 cases $(17.3 \%)$.

In our study, the mean age of the included cases was 37.08 years (range, 1-75 years). On performing correlation, age was significantly associated with recurrence after surgery $(p=0.003)$. Besides, binary logistic regression model was statistically significant $(p=0.002)$ on contrary Zaninotto et al., found that patient age was not a significant predictor of recurrence after surgery [9].

In the current study, BMI was not a significant predictor of recurrence after surgery ( $p=0.383)$. The mean value of BMI in our study cases was $24.78 \mathrm{~kg} / \mathrm{m}^{2}$ cases having BMI 30 or more were documented to be more probable to develop choking and vomiting prior to myotomy and to have heartburn events subsequent to myotomy. However, achalasia symptom enhancement was not influenced by the BMI before operation [10].

In our study, patient symptoms (dysphagia, weight loss, and vomiting) did not constitute a significant risk factor for recurrence after myotomy $(p>0.05)$. Another study has reported that the presence of severe dysphagia was a significant risk factor for poor surgical outcomes and recurrence [11].

In the current study, the median duration of symptoms was 24 months (range, 1-240 months). Duration of symptoms was not a significant predictor of recurrence in the current study $(p=0.151)$. In another study, the duration of symptoms had a mean of 24 months in both recurrence and nonrecurrence groups $(p>0.05)$. Consequently, duration of symptoms was not a significant variable between the two groups [9]. 
In this study, neither balloon dilatation, time interval between dilatation and surgery, nor number of dilatation sessions were a significant predictor for recurrence after surgery ( $p>0.05)$.

On the contrary, another studies have reported that preoperative balloon dilatation was a significant risk factor for poor post-operative outcomes [12] In addition, LES length did not constitute a significant risk factor of recurrence in the current study $(p=0.183)$. The study cases had a mean LES length of $3.62 \mathrm{~cm}$ (range, $1-8 \mathrm{~cm}$ ). Zaninotto et al., also reported that LES length was not statistically significant factor for recurrence [9].

When it comes to the barium findings in our study, it was evident that neither esophageal dilatation, nor delayed emptying constituted a significant predictor of recurrence after surgery ( $p=$ 0.568 and 0.824 respectively). Previous studies have stated that sever esophageal dilation with sigmoid esophagus was significantly associated with poor surgical outcomes [13]. Another study showed that patients with stage I-III disease on preoperative evaluation had $90 \%$ satisfactory clinical outcome that was maintained during long-term follow-up, whereas patients with stage IV disease responded only $50 \%$ of the time and even the responders demonstrated symptom deterioration over time [14].

The mean value of post-operative Eckhart Score [a clinical the grading system most frequently used for the evaluation of symptoms of achalasia and of the efficacy of treatment [16], Table (7)], was $4.11 \pm 3.05$ in our study. It was significantly correlated with recurrence after surgery $(p<0.001)$ and it is agree with the study of Zaninotto et al., which revealed that post-operative symptom score was significantly higher in the recurrence groups $(p=0.005)$ [9]

In our study, an extremely tight fundoplication was improbable to be the reason of obstruction of esophageal flow since most cases who underwent pneumatic dilation showed a good response, 19 recurrent cases (57.6\%) were managed via endoscopic balloon dilatation, whereas the rest of recurrent cases were managed by open surgical remyotomy (14 cases $-42.42 \%$ ). In a study by Patti et al., documented a greater rate of resolution of dysphagia subsequent to redo myotomy (90\% of cases) while following the pneumatic dilation (15\% of cases) for unsuccessful 1ry myotomy [15]

In our study, during surgery for recurrent cases, short myotomy was the commonest cause of recurrence (10 cases $-71.42 \%)$, followed by disrupted wrap ( 2 cases - 14.29\%), and fibrosis ( 2 cases $14.29 \%$ ). Our study had several limitations; firstly it is a retrospective single center experience which is liable to selection bias. Secondly, it included a small number of patients duo to rarity of the disease. A future multicenter study including larger number of patients is needed to confirm our finding.

In conclusion, it was evident that age was negatively correlated with recurrence. However, Eckhardt score was positively correlated with it. Moreover, binary logistic regression revealed that younger age is a strong predictor of recurrence after surgical management of achalasia.

\section{References}

1- BOECKXSTAENS G.E., ZANINOTTO G. and RICHTER J.E.: Achalasia. The Lancet, 383 (9911): 83-93, 2014.

2- GOCKEL I., JUNGINGER T. and ECKARDT V. F.: Persistent and recurrent achalasia after Heller myotomy: analysis of different patterns and long-term results of reoperation. Archives of Surgery, 142 (11): 1093-1097, 2007.

3- FUMAGALLI U., ROSATI R., De PASCALE S., PORTA M., CARLANI E., PESTALOZZA A., et al.: Repeated surgical or endoscopic myotomy for recurrent dysphagia in patients after previous myotomy for achalasia. Journal of Gastrointestinal Surgery, 20 (3): 494-499, 2016.

4- TASCONE A.R. and HALBERT C.A.: Management of Achalasia. In Jr., S.D. and Pauli E.M. (Eds.), Clinical Algorithms in General Surgery (pp. 123-125): Springer., 2019.

5- STEFANIDIS D., RICHARDSON W., FARRELL T.M. KOHN G.P., AUGENSTEIN V. and FANELLI R.D.: SAGES guidelines for the surgical treatment of esophageal achalasia. Surgical Endoscopy, 26 (2): 296-311, 2012.

6- CAMPOS G.M.. VITTINGHOFF E., RABL C., TAKATA M., GADENSTÄTTER M., LIN F., et al.: Endoscopic and surgical treatments for achalasia: A systematic review and meta-analysis: LWW, 2009.

7- JEANSONNE L.O., WHITE B.C., PILGER K.E., SHANE M.D., ZAGORSKI S., DAVIS S.S., et al.: Ten-year followup of laparoscopic Heller myotomy for achalasia shows durability. Surgical Endoscopy, 21 (9): 1498-1502, 2007.

8- CSENDES A., BRAGHETTO I., BURDILES P., KORN O., CSENDES P. and HENRÍQUEZ A.: Very late results of esophagomyotomy for patients with achalasia: Clinical, endoscopic, histologic, manometric, and acid reflux studies in 67 patients for a mean follow-up of 190 months. Annals of Surgery, 243 (2), 196, 2006.

9- ZANINOTTO G., COSTANTINI M., PORTALE G., BATTAGLIA G., MOLENA D., CARTA A., et al.: Etiology, diagnosis, and treatment of failures after laparoscopic Heller myotomy for achalasia. Annals of Surgery, 235 (2), 186, 2002.

10- RAKITA S., VILLADOLID D., KALIPERSAD C., THOMETZ D. and ROSEMURGY A.: BMI affects presenting symptoms of achalasia and outcome after Heller myotomy. Surgical Endoscopy, 21 (2): 258-264, 2007. 
11- KHAJANCHEE Y.S., KANNEGANTI S., LEATHERWOOD A.E., HANSEN P.D. and SWANSTRÖM L.L.: Laparoscopic Heller myotomy with Toupet fundoplication: Outcomes predictors in 121 consecutive patients. Archives of Surgery, 140 (9): 827-834, 2005.

12- ZANINOTTO G., COSTANTINI M., RIZZETTO C., ZANATTA L., GUIRROLI E., PORTALE G., et al.: Four hundred laparoscopic myotomies for esophageal achalasia: A single centre experience. Annals of surgery, 248 (6): 986-993, 2008.

13- SCHUCHERT M.J., LUKETICH J.D., LANDRENEAU R.J., KILIC A., GOODING W.E., ALVELO-RIVERA M., et al.: Minimally-invasive esophagomyotomy in 200 consecutive patients: Factors influencing postoperative outcomes. The Annals of Thoracic Surgery, 85 (5): 1729$1734,2008$.
14- TSIAOUSSIS J., ATHANASAKIS E., PECHLIVANIDES G., TZORTZINIS A., GOUVAS N., MANTIDES A., et al.: Long-term functional results after laparoscopic surgery for esophageal achalasia. The American Journal of Surgery, 193 (1): 26-31, 2007

15-PATTI M.G., MOLENA D., FISICHELLA P.M., WHANG K., YAMADA H., PERRETTA S., et al.: Laparoscopic Heller myotomy and Dor fundoplication for achalasia: Analysis of successes and failures. Archives of Surgery, 136 (8): 870-877, 2001.

16- GOCKEL I. and JUNGINGER T.: The value of scoring achalasia: A comparison of current systems and the impact on treatment the surgeon's view point. Am. Surg., 73 (4): 327-331, 2007.

\section{ارتجاع تعذر ارتخاء عضلة الفؤاد بعد العلاج الجراحى}

هقدمة: تعد عملية هيلر لشق عضلة الفؤاد مع تورية جزئية بجزء من المعدة عن طريق منظار البطن الجراحى هى العملية الأساسية لعلاج الجراحى لمرضى تعذر ارتخاء عضلة الفؤاد. يرتبط فشل العلاج الجراحى لأسباب مختلفة لم يتم تصديدها بشكل قاطع الجع.

الطرق: هذه دراسة بأثر رجعى أجريت على المرضى الذين خضعوا لتخخلات جراحية لمرض تعذر ارتخاء فى مركز جراحة الجهاز الهضمى،

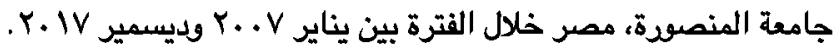

الهدف من هذه الدراسة: هو تحليل تتبؤات مختلة تكرار الإصابة بمرضى ارتجاع تعذر ارتخاء عضلة الفؤاد بعد العلاج الجراحى.

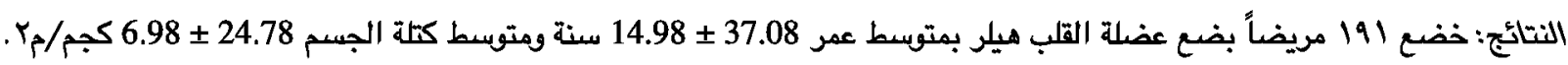

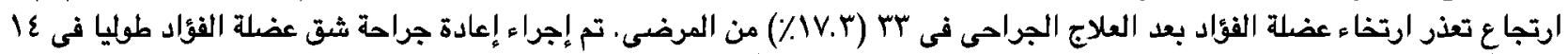

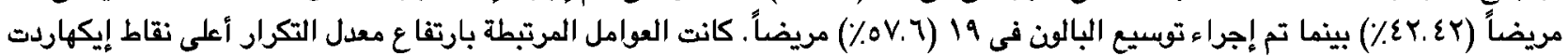

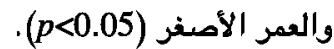

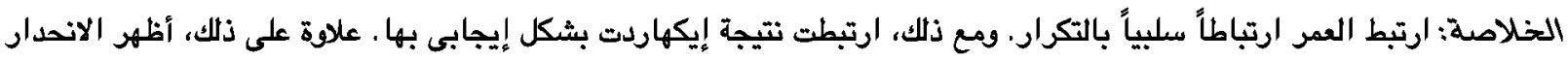

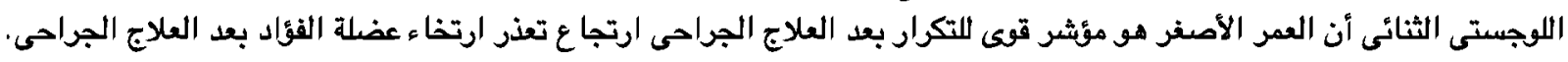

